\title{
Free Open Source Software: FOSS Based GIS for Spatial Retrievals of Appropriate Locations for Ocean Energy Utilizing Electric Power Generation Plants
}

\author{
Kohei Arai ${ }^{1}$ \\ Graduate School of Science and Engineering \\ Saga University \\ Saga City, Japan
}

\begin{abstract}
Free Open Source Software: FOSS based Geographic Information System: GIS for spatial retrievals of appropriate locations for ocean wind and tidal motion utilizing electric power generation plants is proposed. Using scatterometer onboard earth observation satellites, strong wind coastal areas are retrieved with FOSS/GIS of PostgreSQL/GIS. PostGIS has to be modified together with altimeter and scatterometer database. These modification and database creation would be a good reference to the users who would like to create GIS system together with database with FOSS.
\end{abstract}

Keywords- free open source software; postgres SQL; GIS; spatial retrieval.

\section{INTRODUCTION}

Geographic Information System: GIS is used for exploration and spatial retrieval of appropriate locations and areas. GIS software is widely available now a day [1]. GIS can be created with Free Open Source Software: FOSS [2]. Functionalities of GIS is as follows,

- Display superimposing the thematic maps and imagery data

- Spatial and temporal retrieval of the maps and data

- Quantitative analysis (length, area, etc.)

- Simulation (assessment, 3D scenery analysis, etc.)

There are the following issues should be discussed,

- Difficulty on customization of the GIS to specific applications

- Expensive system and database updating cost

- Reverse retrievals for the spatial and temporal search for confirmation of the original data

- Apply image processing to the retrieved data

In order to overcome the aforementioned problems of FOSS ${ }^{1}$ based GIS, example of customization of PostgreSQL ${ }^{2} / \mathrm{GIS}$ (PostGIS ${ }^{3}$ ) for the specific purpose of

\footnotetext{
${ }^{1}$ http://e-words.jp/w/FOSS.html

${ }^{2} \mathrm{http}: / /$ www.postgresql.org/

${ }^{3}$ http://postgis.refractions.net/
}

spatial retrieval of ocean energy ${ }^{4}$, or marine energy ${ }^{5}$, ocean wind and tidal motion utilizing power generation plant locations are attempted.

In order for that, retrievals of the appropriate ocean areas in the Japanese vicinity for exploration of ocean related energy sources, geoid, ocean winds, wave heights and tidal effects are required [3]. The data for the aforementioned energy sources are available from satellite based radar altimeter ${ }^{6}$ and scatterometer ${ }^{7}$. Then exploration of possible areas for ocean related power generations is followed by [4], [5]. Also, create the database containing geoid $^{8}$, tides, ocean winds, wave height and so on from the NASA/JPL PODAAC ${ }^{9}$ (Topex/Poseidon ${ }^{10}$ and Jason satellites ${ }^{11}$ data) by extracting the geo-referenced and time stamped data from the PODAAC has to be done. After that, access to the database through $\mathrm{php}^{12}$ and Mapscript ${ }^{13}$ then display the retrieval results of the appropriate ocean areas for the ocean energy exploration on the php web browser. These procedures are demonstrated in this paper. Also the GIS is used as Neural Network [6], [7].

The following section describes the proposed PostGIS followed by the data descriptions required for spatial retrievals of appropriate locations for electric power generation plants utilizing ocean energy. Then demonstration is followed by. Finally, conclusion and some discussions are followed.

\section{PROPOSED FOSS/GIS}

\section{A. Availability of FOSS/GIS}

There are not so small numbers of FOSS/GIS systems which are available and downloadable from their web sites. Table 1 shows just a small portion of available FOSS/GIS. As for the well-known Grass of GIS, it is easy to install it on your computer through the following procedure,

\footnotetext{
${ }_{5}^{4} \mathrm{http} / / / \mathrm{www} \cdot$ renewableenergyworld.com/rea/tech/ocean-energy

${ }^{5} \mathrm{http} / / /$ en.wikipedia.org/wiki/Marine_energy

${ }^{6} \mathrm{http}: / /$ en.wikipedia.org/wiki/Radar_altimeter

${ }^{7} \mathrm{http}: / /$ en.wikipedia.org/wiki/Scatterometer

${ }^{8} \mathrm{http}: / /$ en.wikipedia.org/wiki/Geoid

${ }^{9} \mathrm{http}: / /$ podaac.jpl.nasa.gov/

${ }_{11}^{10} \mathrm{http} / / /$ sealevel.jpl.nasa.gov/

http://ilrs.gsfc.nasa.gov/satellite_missions/list_of_satellites/jas2_general.html

${ }^{12} \mathrm{http}: / /$ ja.wikipedia.org/wiki/PHP:_Hypertext_Preprocessor

${ }^{13} \mathrm{http}: / /$ mapserver.org/mapscript/index.html
} 
Link to Grass of GIS software

Installation of GRASSLink ${ }^{14} \mathrm{~s}$

GRASSLinks is web interface for GRASS GIS of PDS installation

Before using GRASSLinks, GRASS GIS has to be installed

Information on Installation of GRASS is available from the http://www.media.osaka-cu.ac.jp/ raghavan/grassinfo/.

TABLE I. EXAMPLES OF AVAILABLE FOSS/GIS

\begin{tabular}{|l|l|l|l|}
\hline Tool & Category & Functionality & Remarks \\
\hline MapServer ${ }^{15}$ & $\begin{array}{l}\text { Web Mapping } \\
\text { engine }\end{array}$ & $\begin{array}{l}\text { Thematic and the } \\
\text { other } \begin{array}{l}\text { generation ans } \\
\text { services }\end{array}\end{array}$ & $\begin{array}{l}\text { Useful tool for } \\
\text { map services }\end{array}$ \\
\hline PostGIS & $\begin{array}{l}\text { RDBMS } \\
\text { middleware } \\
\text { extension }\end{array}$ & $\begin{array}{l}\text { Space retrievals } \\
\text { extending data types } \\
\text { to the PostgreSQL }\end{array}$ & $\begin{array}{l}\text { Useful tool for } \\
\text { geological } \\
\text { retrieval services }\end{array}$ \\
\hline Grass ${ }^{16}$ Ver.6 & $\begin{array}{l}\text { Client based } \\
\text { GIS software }\end{array}$ & $\begin{array}{l}\text { Geological contents } \\
\text { management }\end{array}$ & $\begin{array}{l}\text { Useful tool for } \\
\text { register and } \\
\text { edition of the } \\
\text { contents }\end{array}$ \\
\hline
\end{tabular}

As for the well-known Mapserver, it is easy to install it on your computer through the following procedure,

MapServer international version (i18n) (i18n Version of Mapserver: Package)

MapServer 4.0.1 source code and patch for the international use

As for the well known PostgreSQL/GIS, PostGIS, it is easy to install it on your computer through the following procedure,

PostGIS allows store the objects in concern to the GIS (Geographic Information Systems) database

PostgtreSQL extension of PostGIS supports fundamental functions for analysis of GIS objects and spatial R-Tree index of the GiST base

PostgreSQL can be downloaded from the http://www.postgresql.org/

PostGIS is source code tree of the PostgreSQL and can be installed by using the definition of installation process of the PostgreSQL

PostGIS can be compiled with GNU $\mathrm{C}^{17}$, gcc and/or ANSI $\mathrm{C}^{18}$ complier

\footnotetext{
${ }^{14} \mathrm{http} / / / \mathrm{ipp}$ 2.orst.edu/glinks/

${ }^{15} \mathrm{http}: / /$ mapserver.org/

${ }^{16} \mathrm{http} / / /$ grass.fbk.eu/

${ }^{17} \mathrm{http} / / /$ gcc.gnu.org/

${ }^{18} \mathrm{http} / / /$ ja.wikipedia.org/wiki/C\%E8\%A8\%80\%E8\%AA\%9E
}

GNU Make, gmake and/or make can be used for making the PostGIS. GNU make is the default version of make. Version can be confirmed with "make $-v$ ". Make file of PostGIS will not be processed properly when the different version of make is used

Proj4 is the library of the map projection conversion tools as one of the options of the PostGIS. Proj4 is available from the http://www.remotesensing.org/proj

In order to utilize Mapserver, the following procedure is required,

Minnesota Mapserver is the internet Web mapping server and is compatible to the mapping server specification

Mapserver is available from the http://mapserver.gis.umn.edu/

Web Map specification of OpenGIS is available from the http://www.opengis.org/techno/specs/01-047r2.pdf

\section{B. FOSS of GIS}

The required systems are as follows,

PostgreSQL

FOSS of relational database system

SQL: Structured Query Language

PostGIS

GIS extension of PostgreSQL

Good interface to the GIS database

MapServer

Web mapping engine

Database access with php and MapScript

MapServer(php/MapScript)

php

Interface to database with php

Retrievals are then available through php Web page

Submit queries then the retrieved results are displayed from the database table

MapScript

Map engine allows displaying the retrieved results superimposing the other existing thematic maps

Multiple layers

Raster and vector data of maps, meshed data and images through the php web browser

\section{Example of Database Creation}

Conversion of binary data to GIS database is required together with analysis program. After that, Modification of the analysis program is required followed by extraction of the required data. Conversion of the extracted data to GIS database (database table can be created with PostgreSQL) is 
also required. Table 2 shows example of the database in PostGIS. Database is described with table style.

\section{TABLE II. EXAMPLES OF DATABASE IN POSTGIS}

BEGIN;

CREATE TABLE "MGB132.001" (gid serial, "days" int8, "msecs" int8, "Lon_Tra" float8, "L SELECT AddGeometryColumn(", 'MGB132.001', 'the_geom', '4326', 'POINT', 2);

INSERT INTO "MGB132.001" (gid,"days", "msecs", "Lon_Tra", "Lat_Tra"," "SWH_k","H_HSS","Wind INSERT INTO "MGB132.001" (gid,"days", "misecs", "Lon_Tra", "Lat_Tra", "SWH_K","H_HSS","Wind INSERT INTO "MGB132.001" (gid,"days", "msecs", "Lon_Tra", "Lat_Tra", "SWH_k","H_HSS","Wind INSERT INTO "MGB132.001" (gid,"days"," "msecs", "Lon_Tra", "Lat_Tra","SWH_k","H_HSS","Wind INSERT INTO "MGB132.001" ( gid,"days","msecs","Lon__tra","Lat_Tra","SWH_K","H_HSS","Win

Editing of the database can be done in accordance with PostgresSQL data manipulation as shown in Fig.1. Fig.2 shows example of PostgresSQL database server.

\begin{tabular}{|c|c|c|c|c|c|c|c|c|c|c|c|c|}
\hline \multicolumn{13}{|c|}{ का 98} \\
\hline & oid & $e_{\text {mid }}^{\text {sid }}$ & $\underset{\substack{\text { days } \\
\text { inte }}}{x}$ & 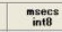 & $\begin{array}{l}\text { Lon Tha } \\
\text { thoate }\end{array}$ & 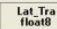 & 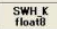 & 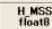 & $\begin{array}{l}\text { Wind Sp } \\
\text { thloati }\end{array}$ & Geo Bad-1 & 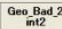 & \\
\hline & 272445 & & 119203 & 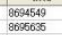 & $\begin{array}{l}17112505 \\
17250090\end{array}$ & 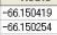 & 32 & 15569 & 17 & & & 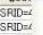 \\
\hline & 27436 & & 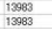 & 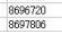 & $\begin{array}{l}17792991 \\
17528079\end{array}$ & 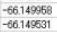 & 32 & 15555 & 27 & & & 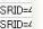 \\
\hline & 27439 & & 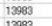 & 66030991 & $\begin{array}{l}17664462 \\
10302027\end{array}$ & . 66149972 & 32 & 155601 & 44 & & & \\
\hline & 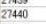 & & 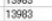 & & 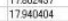 & & & 1515634 & & & & 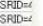 \\
\hline & 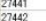 & & 139283 & 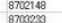 & 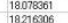 & 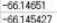 & 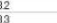 & $\begin{array}{l}15681 \\
15721\end{array}$ & 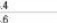 & & & 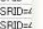 \\
\hline & 27443 & & 13983 & 8700319 & 183564239 & -681421313 & 32 & 15798 & 15 & & & 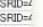 \\
\hline & tints & & 13803 & 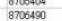 & & 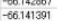 & & 515947 & & & & \\
\hline & & & & 870755 & 18787894 & 606195894 & & & & & & STRD= \\
\hline & 7489 & & 139283 & 8720746 & 190002556 & 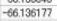 & & 161774 & $\frac{15}{15}$ & & & 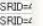 \\
\hline & 272459 & & 130303 & 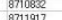 & 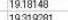 & 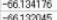 & a3 & 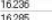 & 19 & & & 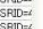 \\
\hline & 2751 & & 13983 & 8773000 & 1945757 & -66129783 & & 16326 & & & & SADOA $=$ \\
\hline & 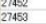 & & 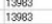 & 8747174 & 10 & 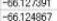 & ${ }^{33}$ & 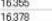 & & & & SRlO=S \\
\hline & & & 13989 & 8770258 & & 801212293 & 33 & 18401 & 14 & & & 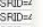 \\
\hline${ }^{23}$ & 7456 & & 139283 & 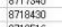 & 201455817 & 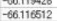 & 35 & 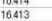 & 15 & & & 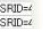 \\
\hline & 7458 & & 13893 & 87775606 & $\begin{array}{l}20283115 \\
20202067\end{array}$ & 606113606 & 22 & 169068 & & & & \\
\hline & & & & & & 60 & 32 & 16392 & & & & SADD $=$ \\
\hline & & & & & 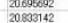 & 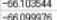 & $3^{3}$ & $\begin{array}{l}10601 \\
16027\end{array}$ & & & & SRDD=S \\
\hline & 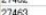 & & & & 2097065 & 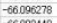 & 34 & 16456 & i1 & & & SRDOA \\
\hline 31 & 7464 & & & & 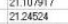 & 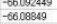 & (34) & $\begin{array}{l}16249 \\
16598\end{array}$ & & & & 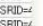 \\
\hline & & & & 8720198 & 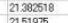 & 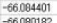 & 34 & 16557 & & & & 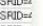 \\
\hline 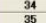 & 74787 & 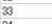 & 130203 & 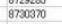 & 212565025 & 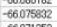 & (33 & 165602 & & & & S $800=$ \\
\hline 36 & 74899 & & 19583 & $\begin{array}{l}87375051 \\
872541\end{array}$ & 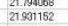 & 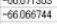 & 33 & 16556 & 66 & & & \\
\hline${ }_{38}^{37}$ & $\begin{array}{l}2740 \\
2747\end{array}$ & ${ }_{37}^{\infty 6}$ & 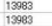 & $\begin{array}{l}87362727 \\
8832712\end{array}$ & 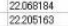 & $\begin{array}{l}-660620505 \\
-6655737\end{array}$ & 32 & $\begin{array}{l}165567 \\
16528\end{array}$ & 75 & & & 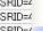 \\
\hline 9084 i7 & & & & & & & & & & & & \\
\hline
\end{tabular}

Figure 1 Editing of the database can be done in accordance with PostgresSQL data manipulation

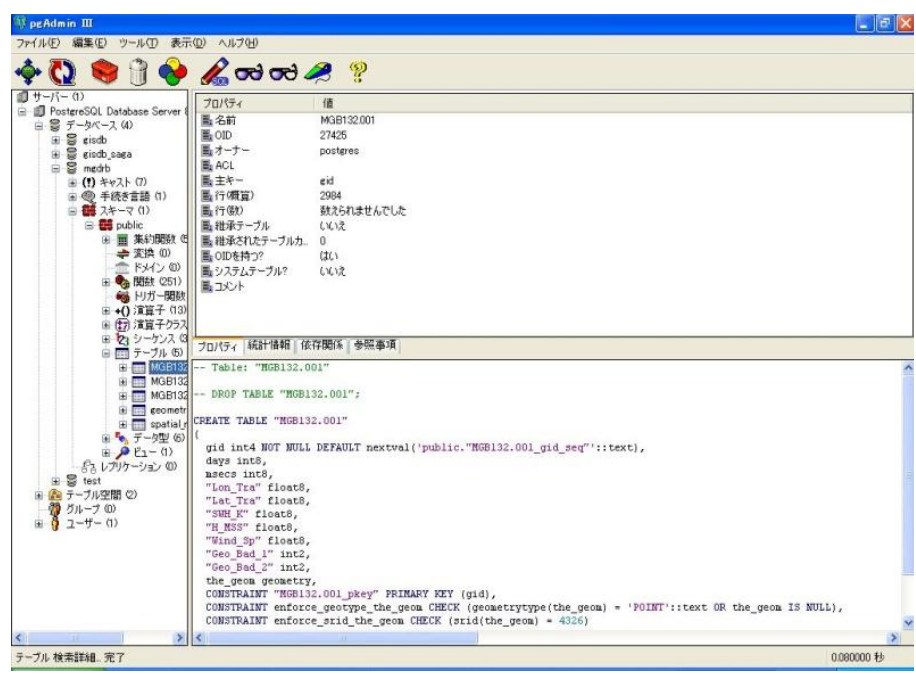

Figure 2 Example of PostgresSQL database server

\section{The Data Required for Spatial Retrievals of Appropriate Locations for Ocean Energy Utilizing Electric Power Generation Plants}

There are some of required data for finding appropriate locations of ocean energy utilizing electric power generation plants. Namely,

\section{(1) Topex/Poseidon}

Topex/Poseidon was launched on Aug. 10 1992. This is the joint mission between U.S.A. and France. Specific features are the followings,

Microwave altimeter

Non sun-synchronous

Inclination: $66^{\circ}$

Global coverage within 10 days

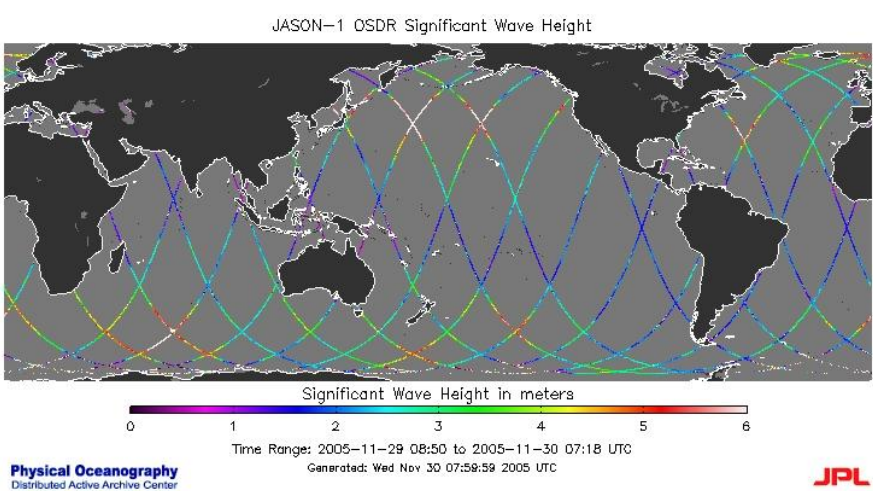

Figure 3 Topex/Poseidon observes ocean surface along with its orbit

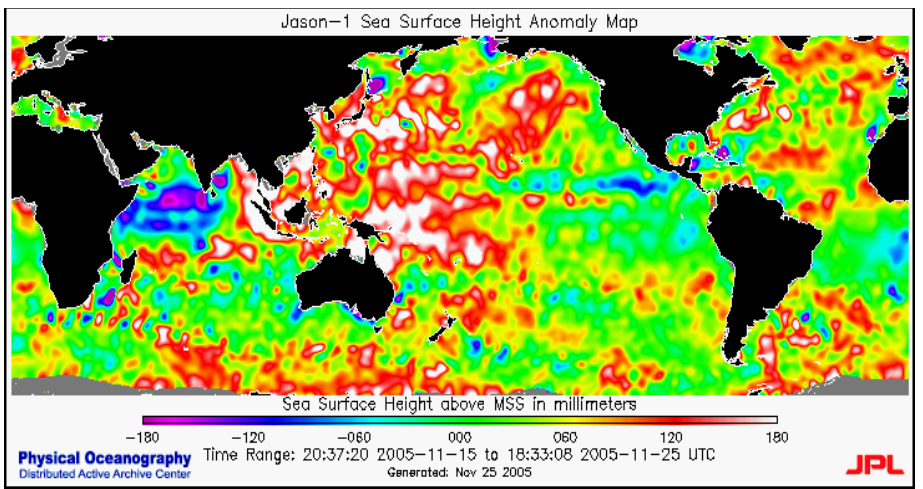

Figure 4 Geoid potential and wave height is estimated with the altimeter onboard Topex/Poseidon satellite

\section{(2) Scatterometer}

Ocean wind direction and speed can be estimated with scatterometer data. One of the scatterometers onboard satellites is SeaWinds ${ }^{19}$ on Advanced Earth Observing Satellite: ADEOS-II ${ }^{20}$. Major specification of SeaWinds is shown in Table 3.

\footnotetext{
${ }^{19} \mathrm{http}$ //winds.jpl.nasa.gov/missions/seawinds/

${ }^{20} \mathrm{http}: / /$ en.wikipedia.org/wiki/ADEOS_II
} 


\section{TABLE III. MAJOR SPECIFICATION OF SEAWINDS}

Radar: 13.4 gigahertz; 110 -watt pulse at 189-hertz PRF

Antenna: $\quad$ 1-meter-diameter rotating dish producing 2 spot beams sweeping in a circular pattern

Mass:

200 kilograms

Power:

220 watts

Average Data

40 kilobits per second

Rate:

Along with satellite orbit, scatterometer observes ocean surface as shown in Fig.5. Global coverage can be done. Then ocean wind direction and speed is estimated as shown in Fig.6 (a), (b).

5 days average of wind speed and vector wind is shown in Fig.6 (a) while 5 days average of dynamic height ${ }^{21}$ and winds are shown in Fig.6 (b), respectively.

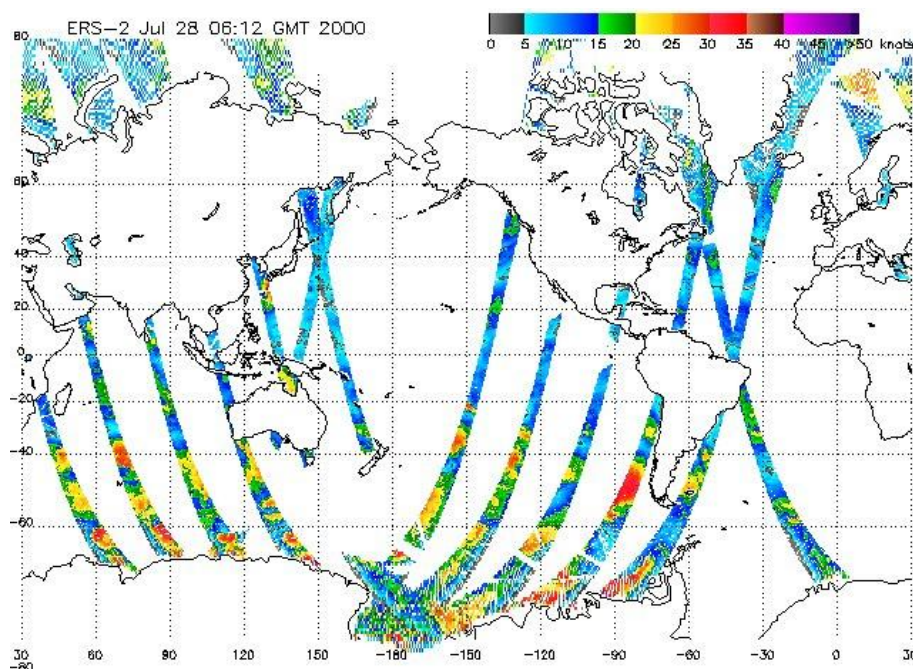

Figure 5 Example of scatterometer observed ocean wind along with satellite orbit.

TAO/TRITON 5-Day Scalar Wind Speed and Vector Winds $\left(\mathrm{m} \mathrm{s}^{-1}\right)$ Ending on December 232004
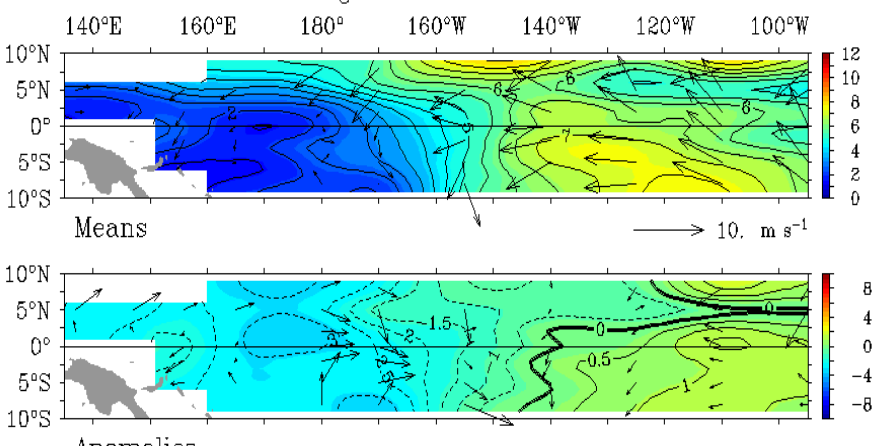

Anomalies

TAO Project Dffice/PMEL/NOAA

(a)Wind speed and vector winds

${ }^{21}$ http://www.euro-

argo.eu/content/download/21538/311050/file/04_guinehut_euro_argo_01.pdf
TAO/TRITON 5-Day Dynamic Height (0/500 dbar, dyn. $\mathrm{cm}$ ) and Winds $\left(\mathrm{m} \mathrm{s}^{-1}\right)$
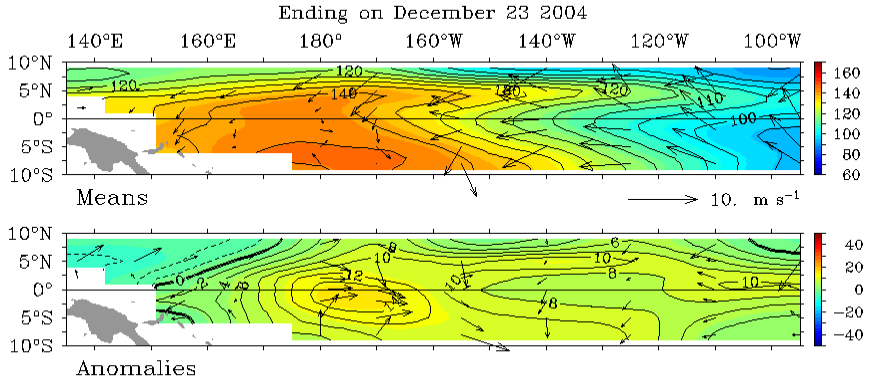

TAO Project Office/PMEL/NOAA

(b)Dynamic height and winds

Figure 6 Example of estimated ocean wind direction and speed

\section{EXPERIMENTS WITH THE PROPOSED FOSS/GIS}

From the MapServer site, Japan and its vicinity of map is downloaded. Web site is designed with php. Under the web site, there is the PostGIS with the databases of Topex/Poseidon altimeter data derived geoid and significant wave height as well as ADEOS-II scatterometer (SeaWinds) data derived wind direction and wind speed. Through web site, search conditions of ocean wind speed, significant wave height, and geoid can be input using radio button. Then search results are obtained after the input. If the search condition of wind speed (it is greater than $20 \mathrm{~m} / \mathrm{s}$ ) is input, then spatial retrieval result is displayed as shown in Fig.7.

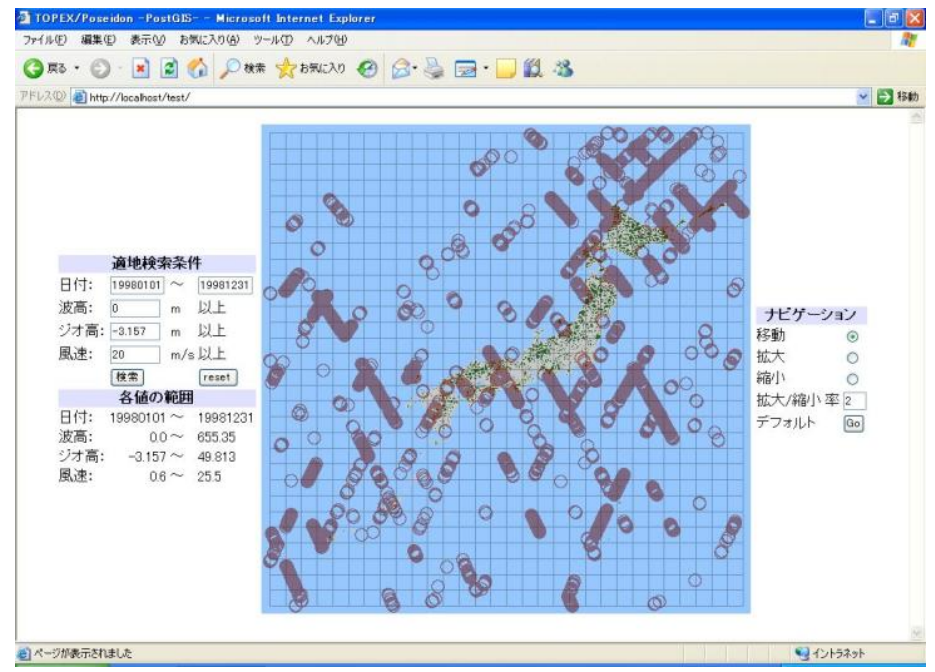

Figure 7 Spatial retrieval result with the condition of which wind speed is greater than $20 \mathrm{~m} / \mathrm{s}$

Spatial retrieval result with the search condition of which geoid potential is greater than $40 \mathrm{~m}$ is shown in Fig.8. Also, spatial retrieval result with the search condition of which geoid potential is greater than $40 \mathrm{~m}$ and wind aped is greater than $20 \mathrm{~m} / \mathrm{s}$ is shown in Fig.9. Meanwhile, Fig.10 shows spatial retrieval result with the search conditions of which wind speed, significant wave height, geoid potential, and the distance from the nearest coastal lines. Such these spatial retrievals are specific feature of GIS. 


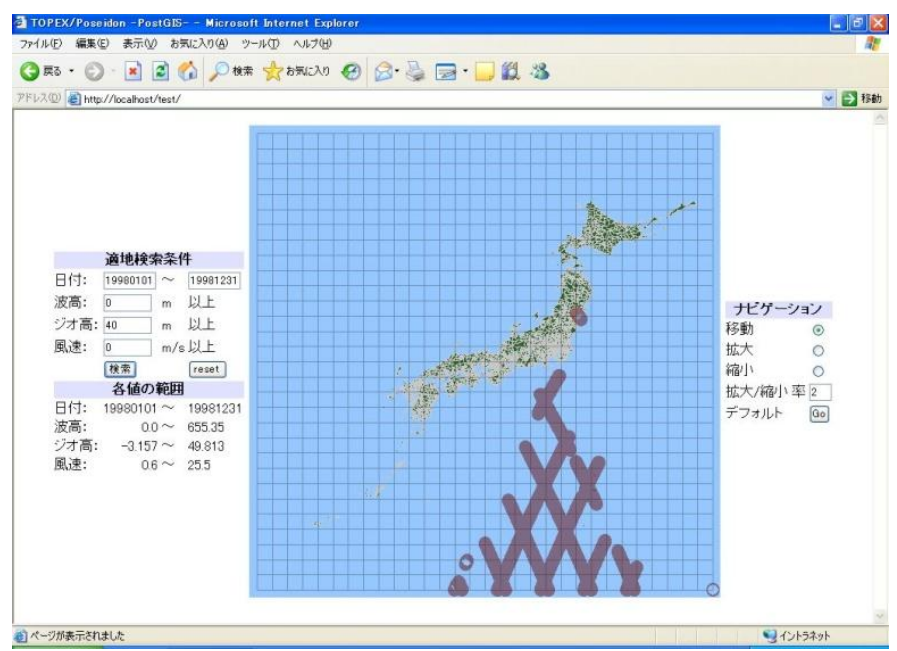

Figure 8 Spatial retrieval result with the search condition of which geoid potential is greater than $40 \mathrm{~m}$

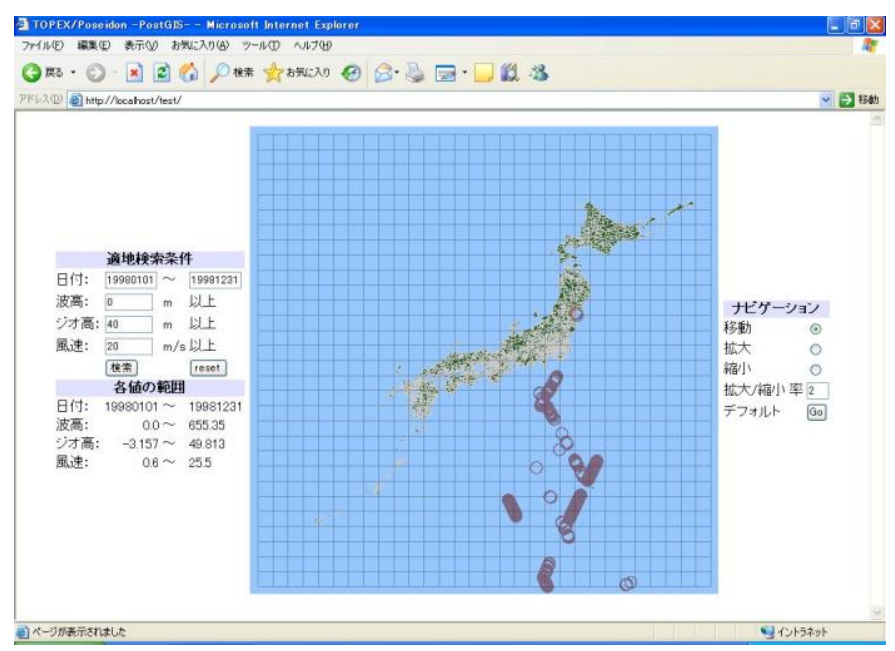

Figure 8 Spatial retrieval result with the combined conditions between wind speed (greater than $20 \mathrm{~m} / \mathrm{s}$ ) and geoid potential (greater than $40 \mathrm{~m}$ ).

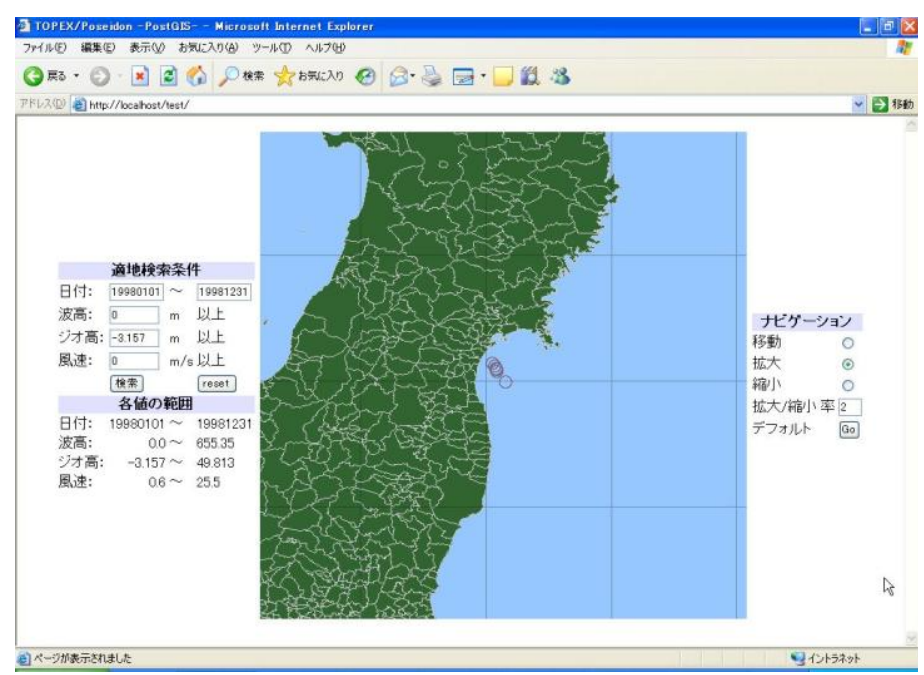

Figure 9 Spatial retrieval result with the search conditions among wind speed, significant wave height, geoid potential, and the distance from the nearest coastal lines.

\section{CONCLUSION}

Customization can be done smoothly. It is easy to customize the PostGIS (extension of PostgreSQL) with Mapserver through the php. Also, it is confirmed that the most of functionalities of PostGIS (Submittion of queries, retrievals of the appropriate data from the database, display the retrieved results on the php web browser). Furthermore, image processing and analysis are also available and can be applied to the retrieved data.

Because the proposed PostGIS is modified version of free open source software, everybody may download and install and modify easily. The proposed system is open to the public upon request with the condition of credibility of the name of Arai/Saga University.

\section{ACKNOWLEDGMENT}

The author would like to thank to Mr. Shuichi Uchiyama for his effort to the experiments.

\section{REFERENCES}

[1] Kohei Arai, Earth observation satellite imagery data processing methods by means of Java language, Morikita Publishing Inc., 2001.

[2] Kohei Arai, Free Open Source Software GIS, Proceedings of the Computer Assisted Teaching Conference (CATCON 2006), ISPRS Technical Commission VI Symposium"E-LEARNING AND THE NEXT STEPS FOR EDUCATION” 2006

[3] Kohei Arai, Open GIS with spatial and temporal retrievals as well as assimilation functionality, Proceedings of the Asia Pacific Advanced Network Natural Resource Workshop, Utilization of Earthy Observation Satellite-Digital Asia Special Session 1,p. 8, 2003.

[4] Kohei Arai, Measuring and analysing methods for ocean environment by means of satellite remote sensing, Proceedings of the Advanced Science and Technology for Utilization of Ocean Energy, p11, 7, 2007.

[5] Kohei Arai, Ocean environment measuring and ocean energy exploration methods by means of satellite remote sensing, Proceddings of the Advanced Science and Technology for Utilization of Ocean Energy, p46-53, 7, 2007.

[6] Kohei Arai, Geographic information system: GIS based on neural network for appropriate parameter estimation of geophysical retrieval equations with satellite remote sensing data, Proceedings of the IEEE Geoscience and Remote Sensing, PID 220128, 2006.

[7] K.Arai, Sea Surface Temperature estimation method for ocean areas and seasons using Geographic Information System as a neural network, Sediment and Ecohydraulics, Proc.in Marine Science, 9, Elsevier ISBN978-0-444 53184-1, 2007.

\section{AUTHORS PROFILE}

Kohei Arai, He received BS, MS and PhD degrees in 1972, 1974 and 1982, respectively. He was with The Institute for Industrial Science, and Technology of the University of Tokyo from 1974 to 1978 also was with National Space Development Agency of Japan (current JAXA) from 1979 to 1990. During from 1985 to 1987, he was with Canada Centre for Remote Sensing as a Post Doctoral Fellow of National Science and Engineering Research Council of Canada. He was appointed professor at Department of Information Science, Saga University in 1990. He was appointed councilor for the Aeronautics and Space related to the Technology Committee of the Ministry of Science and Technology during from 1998 to 2000 . He was also appointed councilor of Saga University from 2002 and 2003 followed by an executive councilor of the Remote Sensing Society of Japan for 2003 to 2005 . He is an adjunct professor of University of Arizona, USA since 1998. He also was appointed vice chairman of the Commission "A" of ICSU/COSPAR in 2008. He wrote 30 books and published 332 journal papers. 